\title{
XXVII ENCUENTRO NACIONAL DE FORMADORES DE SEMINARIOS
}

\author{
Pbro. César Augusto Torres
}

El autor es Vicerrector y Formador del Seminario Metropolitano "Inmaculada Concepción" de la Arquidiócesis de Buenos Aires.

Sólo con el paso del tiempo las cosas vividas empiezan a mostrar su verdadero contenido y valor. Pero además, hacen falta una mirada y un corazón atentos para saber descubrir la hondura de esos acontecimientos.

Del 5 al 9 de Febrero de este año tuvo lugar, en el Seminario de Buenos Aires, el XXVII Encuentro Nacional de Formadores, organizado por la OSAR, la "Organización de Seminarios de Argentina". Estos encuentros comenzaron a realizarse hace muchos años, antes inclusive de que se les diera este título "oficial". ¿El motivo? La Iglesia fue entendiendo la necesidad y la urgencia de "formar a los formadores" de los futuros sacerdotes. Fue y es un reflejo de su atenta maternidad.

A lo largo de los años estos encuentros se realizaron en diferentes lugares del país: Jujuy, Salta, Tucumán, Chaco, Córdoba,
Buenos Aires, La Plata, Bariloche, Mendoza, Rosario... No hace falta decir la riqueza de esa variedad, pues se podían conocer distintos Seminarios, estilos sacerdotales, acentos formativos, etc., dentro de una gran comunión de fe y vocación, pues, en última instancia, estamos llamados por el mismo Señor, a la misma misión: formar pastores según el corazón del Buen Pastor.

Los temas tratados en los encuentros también han sido variados, intentando iluminar los desafíos que la tarea formativa enfrenta.

Este año el tema que recorrió el Encuentro fue la presentación de la Ratio Fundamentalis Institutionis Sacerdotalis (RFIS), es decir, las normas universales para la formación sacerdotal, publicadas el 8 de Diciembre de 2016. Estas normas son "aterrizadas" luego por cada país, teniendo en cuenta su realidad 
particular. La última "encarnación" de la Ratio se da en cada Seminario a través de un Proyecto Formativo.

Por supuesto, un tema tan importante "pedía" alguien que estuviera a la altura de la cuestión. Y ese "alguien" fue Mons. Jorge Carlos Patrón Wong, Secretario para los Seminarios, de la Congregación Vaticana para el Clero. Él no sólo "conoce" la Ratio, sino que ha participado activamente en su gestación y redacción. Es por eso que invitarlo, sabiendo la multitud de compromisos que tiene, fue la mejor apuesta que los formadores pudimos hacer hace ya más de un año, cuando pensábamos en este Encuentro.

Mons. Patrón Wong nos fue llevando de la mano por distintos temas: la aplicación de la Ratio, los agentes de la formación, las dimensiones de la formación, las distintas etapas del itinerario formativo, el clima fraterno que debe reinar en los Seminarios...

Uno de los temas en que insistió con mucha fuerza fue el de la "unicidad" del camino formativo. No es una "novedad" en sentido propio, pero sí una idea que ha ganado fuerza y presencia en los últimos años. Así lo plantea la misma Ratio:

La formación de los sacerdotes es la continuación de un único «camino discipular», que comienza con el bautismo, se perfecciona con los otros sacramentos de la iniciación cristiana, es reconocido como centro de la vida, en el momento del ingreso al Seminario, $y$ continúa durante toda la vida ( $\mathrm{n}^{\circ}$ 3).

Es una concepción muy profunda y hermosa: la vocación de un sacerdote hunde sus raíces en la gracia bautismal, y no deja de crecer y madurar un solo instante, porque en cada rincón de la vida, primero del seminarista y luego del sacerdote, Dios nos sale al encuentro con una nueva gracia formativa.

Las exposiciones fueron muy iluminadoras, llenas de la sabiduría propia de un hombre con mucha experiencia en el tema. Pero fue la persona misma de Mons. Patrón Wong la que dejó huella honda en nosotros: cálido, sencillo y profundo a la vez, cercano, preocupado por la salud espiritual de los formadores. Destilaba pasión por su tarea, y una gran comprensión de los desafíos que hoy enfrenta la formación sacerdotal. Tuvo tiempo para todos, para charlar, tomarse fotos, contestar preguntas, calmar inquietudes... $Y$ en su sencillez y humildad repetía que él "aprendía de nosotros". Hasta pidió tener un momento de encuentro con los seminaristas que estaban colaborando en la organización. Parecía no agotarse nunca.

Otro capítulo es el de haber sido "anfitriones" del Encuentro. Sólo digo que fue una gracia y un honor poder trabajar con los otros formadores del Seminario y los seminaristas, intentando tener todo dispuesto para recibir, como a huéspedes de lujo, a los formadores 
de los seminarios del país. Fueron en total 112. ¿Tarea ardua? No cabe duda, pero es parte de esa gracia enorme que es "trabajar en la viña del Señor", aportando nuestro pequeño grano de arena para la formación de los formadores.

Como decía al comienzo, sólo con el paso del tiempo las cosas vividas empiezan a mostrar su verdadero contenido y valor. Es verdad que no ha pasado tanto tiempo desde la finalización del Encuentro, pero ya empieza a desprender la suave fragancia del paso de Dios por nuestras vidas. Yo pido para todos nosotros la mirada y el corazón atentos para descubrir la hondura de lo que hemos vivido. 